\title{
Oficinas de Programação para Meninas: Despertando o Interesse Pela Computação
}

\author{
Giorgia de O. Mattos, Josilene A. Moreira, Ana Flávia S. A. Moura, Andrea B. \\ Nascimento, Chaenne C. Oliveira \\ Centro de Informática - Universidade Federal da Paraíba (UFPB) \\ Rua dos Escoteiros s/n, Mangabeira - 58.055-000 - João Pessoa - PB - Brazil \\ \{giorgia,josilene\}@ci.ufpb.br, \{anaflavia7x, andrea.bnec, \\ chaecpnoliveira\} @gmail. com
}

\begin{abstract}
The present report describes the activities carried out in an extension project that has been working in the education of students of the first year of high school, promoting, through programming workshops, the real contact with the area of computation. Data collected during the three years of the project show that most of the students do not have prior knowledge about programming and consider the activity difficult; it was also observed that they are motivated, interested and challenged in learning to program and perceive that the area of computation is also for them. From the evaluation at the end of the action, it can be seen that the workshops have been fulfilling their role in promoting female empowerment as well as contributing to the girls' citizenship.
\end{abstract}

Resumo. O presente relato descreve as atividades realizadas em um projeto de extensão que vem atuando na educação de alunas do primeiro ano do ensino médio, promovendo, através de oficinas de programação, o contato real com a área de computação. Dados coletados durante os três anos do projeto mostram que a maioria das alunas não tem conhecimento prévio sobre programação e consideram a atividade dificil; observou-se ainda que elas se mostram motivadas, interessadas e desafiadas em aprender a programar e percebem que a área de computação também é para elas. A partir da avaliação ao final da ação, pôde-se constatar que as oficinas vem cumprindo seu papel na promoção do empoderamento feminino bem como contribuindo com a formação cidadã das meninas.

\section{Introdução}

A presença feminina nas áreas de ciência e tecnologia vem sendo amplamente estudada nos últimos anos [Beaubouef and Zhang 2011] [Oliveira et al 2014]. Segundo o último Censo da Educação Superior do Brasil [INEP 2016], em 2016, as mulheres representaram $44 \%$ dos alunos matriculados nos cursos de graduação porém apenas 14\% delas estavam em cursos da área de Computação [SBC 2016].

Estudos mostram que existe uma série de fatores que levam ao desinteresse pela computação por parte das mulheres [Burge and Suarez 2005] [Beaubouef and Zhang 2011] [Eney et al 2013] [DuBow 2013] [Klawe 2013]. Dentre as principais causas estão a falta de "modelos femininos" na área, o fato das mulheres se sentirem excluídas em 
ambientes (estudantis ou profissionais) dominados por homens, a falta de incentivo para que sigam uma carreira na área e o fato de não se sentirem à vontade com a cultura da computação/tecnologia.

Em 2014 o Centro de Informática da Universidade Federal da Paraíba realizou um diagnóstico com o intuito de levantar as principais dificuldades enfrentadas pelas alunas da graduação tanto para o ingresso como para a permanência nos cursos da área de Ciência da Computação do Centro de Informática [SALES et al 2014]. Segundo o diagnóstico as principais dificuldades para a sua permanência são com as disciplinas de Cálculo e com as disciplinas da área de programação onde apenas 17\% das graduandas já tinham algum conhecimento sobre programação quando iniciaram o curso. Assim, o relato apresentado aqui descreve como o projeto de extensão vem atuando na educação de alunas do primeiro ano do ensino médio, promovendo através das Oficinas de Programação o desenvolvimento do raciocínio lógico e conceitos de programação de computadores. Através de um contato real com a área de programação, o projeto objetiva ser um agente transformador que atraia a atenção das alunas do ensino médio, possibilitando que elas possam conhecer de forma mais abrangente a carreira, antes de sua escolha para o vestibular.

O restante do artigo está organizado como segue: a Seção 2 traz estudos que tratam do ensino de programação para meninas; na Seção 3 são apresentados os materiais e métodos utilizados nas oficinas de programação; na Seção 4 são reportados os resultados obtidos e observados bem como algumas discussões a respeito; e, por fim, as conclusões e perspectivas futuras.

\section{Trabalhos Correlatos}

A programação de computadores é uma atividade base da área de computação e para muitos estudantes ela não é simples. A criatividade, o raciocínio lógico e a capacidade para a resolução de problemas são habilidades fundamentais para o sucesso na programação e estas devem ser estimuladas durante toda a formação escolar do aluno [Cristóvão 2008]. A prática intensiva e a motivação para resolver vários exercícios são itens importantes para o sucesso do aluno [Robins et al 2003].

A programação para meninas ainda é pouco explorada mas alguns estudos sugerem que intervenções feitas pelas universidades, com atividades de programação em escolas podem ser bem eficazes, contribuindo, inclusive, para a diminuição de estereótipos masculinos ligados à computação [Cohoon 2002]. Nos Estados Unidos, por exemplo, iniciativas como "Girls on the GO: The Mobile Computing College Experience" [Burge et al 2013] e a descrita em [Marcu et al 2010] ensinam programação para meninas do ensino médio, procurando incentivar o interesse feminino pela Ciência da Computação.

No Brasil, as pesquisas existentes relatam experiências com alunas do ensino fundamental e médio, onde a programação é utilizada, também, como meio de incentivar a presença feminina na área. O programa Meninas Digitais [Maciel and Bim 2016] da Sociedade Brasileira de Computação tem como objetivo divulgar a área de Computação para despertar o interesse de estudantes do ensino médio/tecnológico ou dos anos finais do ensino fundamental. É uma iniciativa voltada para o público feminino, para que elas conheçam melhor a área e, desta forma, sintam-se motivadas a 
seguir carreira em Computação. O relato apresentado em [Souza et al 2013] descreve as atividades de programação com o Scratch, realizadas com alunas do ensino fundamental. Segundo os autores a utilização de jogos e o ambiente Scratch atraem a atenção e o interesse das meninas pois trabalham habilidades e conceitos básicos de programação de maneira descontraída e divertida; a principal dificuldade foi relacionada a lógica de programação. O projeto Android Smart Girls [Ramos et al 2015] ensina programação para meninas do ensino médio de uma escola de Campinas-SP. A ferramenta de desenvolvimento de aplicativos para dispositivos móveis MIT App Inventor foi utilizada. Em [Mattos et al 2015] os autores descrevem a utilização de kits de robótica educacional para o ensino de programação a meninas. As atividades descritas envolvem as fases de montagem do robô e a sua programação, com ambiente de programação próprio. De modo geral as alunas se mostraram motivadas, interessadas pela atividade e com vontade de aprender mais.

\section{Materiais e Métodos}

As atividades envolvendo as oficinas de programação vem sendo realizadas no Colégio da Polícia Militar Estudante Rebeca Simões, na cidade de João Pessoa, no período 2015-2017, junto às alunas do primeiro ano do ensino médio. A equipe executora é formada por duas professoras do Centro de Informática da UFPB e duas alunas de graduação dos cursos de Ciência da Computação e Engenharia da Computação. Os encontros aconteceram quinzenalmente, de maio a dezembro, com duração de aproximadamente 4 horas cada. As atividades realizadas compreendem aquelas que estão descritas na Tabela 1 bem como os conteúdos abordados em cada etapa e a ferramenta utilizada.

Tabela 1. Descrição das atividades realizadas e conteúdos abordados.

\begin{tabular}{|l|l|l|}
\hline \multicolumn{1}{|c|}{$\begin{array}{c}\text { Atividade } \\
\text { desenvolvida }\end{array}$} & \multicolumn{1}{|c|}{ Conteúdo abordado } & \multicolumn{1}{|c|}{$\begin{array}{c}\text { Ferramenta } \\
\text { utilizada }\end{array}$} \\
\hline $\begin{array}{l}\text { Diagnóstico do } \\
\text { perfil da turma e } \\
\text { palestra de abertura } \\
\text { do projeto }\end{array}$ & $\begin{array}{l}\text { - questões sobre o conhecimento } \\
\text { prévio de programação e raciocínio } \\
\text { lógico } \\
\text { - apresentação dos cursos da área de } \\
\text { Computação oferecidos pelo CI/UFPB }\end{array}$ & $\begin{array}{l}\text { Questionário } \\
\text { Palestras }\end{array}$ \\
\hline $\begin{array}{l}\text { Oficinas com jogos } \\
\text { sérios }\end{array}$ & $\begin{array}{l}\text { - definição do problema } \\
\text { - conceito de instrução } \\
\text { - sequência lógica de instruções }\end{array}$ & Lightbot \\
\hline $\begin{array}{l}\text { Oficinas de } \\
\text { algoritmos }\end{array}$ & $\begin{array}{l}\text { - variáveis } \\
\text { - estrutura sequencial, condicional e } \\
\text { de repetição } \\
\text { - funções } \\
\text { - depuração }\end{array}$ & Code.org \\
\hline $\begin{array}{l}\text { Oficinas de } \\
\text { programação }\end{array}$ & $\begin{array}{l}\text { - implementação dos conceitos } \\
\text { aprendidos nas oficinas de algoritmos }\end{array}$ & $\begin{array}{l}\text { Scratch } \\
\text { App Inventor }\end{array}$ \\
\hline
\end{tabular}




\subsection{Atividade 1: Diagnóstico do perfil da turma e palestra de abertura do projeto}

Esta primeira atividade tem como objetivo conhecer a turma participante das oficinas e, para tal, são aplicados dois questionários. O primeiro contem 13 questões de cunho pessoal sobre programação (conhecimento prévio sobre o assunto) e a utilização de computadores, celular e internet (se utiliza, com que frequência e com que finalidade). O segundo questionário aborda 8 questões simples de lógica como ordenar palavras, sinônimos e antônimos. As informações relevantes destes questionários estão discutidas na próxima seção.

A palestra de abertura do projeto é de responsabilidade do grupo Meninas na Computação do Centro de Informática da UFPB, que desenvolve desde 2014 junto a alunas de escolas públicas, a divulgação dos cursos da área de computação sempre discutindo e estimulando a presença feminina na área. Nesta palestra as alunas conhecem um pouco sobre a atuação e o perfil do profissional de computação, o mercado de trabalho e as histórias de algumas mulheres de destaque na área.

\subsection{Atividade 2: Oficinas com jogos sérios}

A segunda atividade proposta utiliza o jogo sério Lightbot (http://armorgames.com/play/2205/light-bot) e tem como objetivo estimular o raciocínio lógico, a organização do pensamento computacional e a capacidade de solucionar problemas.

O Lightbot é um jogo online composto de três fases (básico, procedimentos e laços) onde um robô precisa se movimentar para acender as luzes dos ladrilhos mais escuros. Para tal, existe um conjunto de comandos (andar, acender, girar e pular) que devem ser organizados de forma que, quando executados em sequência, façam com que o robô atinja o objetivo de cada etapa. $\mathrm{Na}$ fase 1 são abordados conceitos básicos de algoritmos onde o objetivo é organizar os comandos disponíveis para que cada uma das etapas seja cumprida. Na fase 2 são apresentados conceitos de programação em bloco (procedimentos), ou seja, um bloco de comandos pode ser reaproveitado sempre que for necessário. A fase 3 traz conceitos de recursividade, onde um bloco pode chamar a si próprio simplificando e diminuindo a quantidade de comandos utilizados. O objetivo do jogo é completar em até 1 hora todas as fases e ele faz parte do programa "A Hora do Código".

Esta atividade consistiu em duas partes: teórica e prática. Na parte teórica foram selecionadas algumas atividades da fase 1 que foram realizadas numa folha de respostas. Depois de explicado o objetivo do jogo, cada uma das instruções e a atividade proposta, as alunas listaram, na folha de respostas, os comandos necessários para cumprir cada uma das atividades. Na parte prática executaram, utilizando a ferramenta, todas as atividades presentes na folha de respostas e compararam as suas respostas com a realidade do jogo, identificando e entendendo os seus erros.

\subsection{Atividade 3: Oficinas com algoritmos}

A terceira atividade desenvolvida foi trabalhar os conceitos básicos de programação como as estruturas de controle de execução de um programa (sequencial, condicional e de repetição) e conceitos avançados como a programação em blocos (funções e procedimentos), a depuração e a recursividade. 
O ambiente utilizado foi o Code Studio (http://studio.code.org) que é uma parte do Code.org que disponibiliza cursos de programação completos para iniciantes, em diversas faixas etárias, que estejam interessados em aprender a programar. O ambiente divide-se em três áreas: a descrição do problema a ser solucionado, os blocos disponíveis e a área de trabalho onde os blocos são estruturados para solucionar o problema. Traduzido como "A Hora do Código do Brasill", o projeto visa desmistificar a programação e apresentar material de qualidade para que professores e alunos tenham acesso as matérias da área de forma amigável.

Os conteúdos são abordados através de jogos e cada jogo é composto por níveis. O ambiente disponibiliza também os planos de aulas, estatísticas com os níveis concluídos e a quantidade de linhas de código escritas por nível e o progresso individual em cada fase, mostrando, por exemplo, se a fase foi iniciada, se a fase foi concluída com o número adequado de blocos ou com muitos blocos.

\subsection{Atividade 4: Oficinas de programação}

A quarta e última atividade proposta consiste em utilizar um ambiente de programação que permita a criação de um programa, jogo ou aplicativo completo que aborde os conteúdos estudados na atividade 3. As ferramentas utilizadas foram o Scratch para a criação de jogos simples e animados e o MIT App Inventor para a criação de aplicativos para dispositivos com o sistema Android.

O Scratch é uma linguagem de programação gráfica cujo objetivo é auxiliar a aprendizagem de programação de maneira lúdica e criativa, podendo ser usado por crianças desde 8 anos de idade e pessoas que não possuem nenhum conhecimento de programação.

A ferramenta MIT App Inventor é utilizanda por quem não tem experiência em programação para criar aplicativos. O MIT App Inventor é uma plataforma de programação visual criada pela Google em parceria com o MIT (Massachussets Institute of Technology), na qual se pode criar um aplicativo para Android utilizando blocos lógicos de maneira simples e intuitiva.

\subsection{Avaliação}

A avaliação do processo ensino-aprendizagem foi realizada observando-se a turma durante as oficinas e relatando os acontecimentos em cada encontro. As anotações incluíram as dificuldades encontradas para realizar o planejamento do dia (estrutura física de laboratório e internet, por exemplo), se as alunas cumpriram todas as atividades programadas para o encontro, se as alunas cumpriram os desafios propostos, o relato das alunas participantes e o relato das alunas de graduação que conduziram as oficinas.

Ao término do projeto anual foi elaborado um teste com 6 questões de lógica, nos mesmos moldes daquele aplicado na primeira atividade, e mais 4 questões retiradas de provas da Olimpíada Brasileira de Informática - Modalidade Iniciação, onde as tarefas das provas consistem em problemas de lógica e problemas de computação (lógica de programação, mas sem o uso do computador). 


\section{Resultados e Discussões}

Ao longo de 3 anos do projeto de extensão, 18 alunas do $1^{\circ}$ ano do ensino médio participaram efetivamente das oficinas de programação. $O$ projeto não foi idêntico nos 3 anos, especialmente da atividade 4 onde foram utilizadas ferramentas diferentes em 2016 (Scratch) e 2017 (MIT App Inventor). A equipe do projeto é formada por duas professoras e alunas de graduação (bolsistas e voluntárias) dos cursos de Ciência da Computação e Engenharia de Computação que sempre conduziram as oficinas.

O questionário aplicado na atividade 1 nos permitiu conhecer previamente as turmas e consequentemente organizar e planejar melhor as atividades de acordo com os dados levantados. Das respostas obtidas apenas uma aluna já tinha algum conhecimento prévio sobre programação e o grau de dificuldade desta atividade foi considerado 4 (numa escala de 1 a 5 , sendo 5 muito difícil). $72 \%$ delas possuem computador em casa e o utilizam diariamente, o acesso às redes sociais e os jogos online são as principais atividades realizadas por elas. Com relação as questões de lógica, a média de acertos ficou em 3 questões de um total de 8, sendo a questão 2 a que aparece com mais erros. As alunas consideraram as questões difíceis e relataram não entender o enunciado ou não conseguirem identificar o padrão lógico pedido na questão.

O Lightbot foi utilizado em dois momentos distintos: no primeiro momento as alunas receberam a descrição das oito tarefas do primeiro nível do jogo, o conjunto de instruções disponíveis e uma folha de respostas onde deveriam anotar as instruções necessárias para a solução das tarefas; o segundo momento consistiu em jogar o jogo completo em até no máximo 1 hora. A média de acertos das tarefas ficou em $45 \%$, sendo a maior dificuldade na interpretação das instruções (virar a direita, virar a esqueda e utilização da seta para frente ao invés da instrução de pular). O tempo médio para a conclusão do jogo ficou em 54 minutos e ao término da atividade o próprio jogo gera um "Certificado de Conclusão Hour of Code".

$\mathrm{Na}$ terceira atividade foram trabalhados os conceitos básicos de algoritmos e programação com o ambiente Code Studio. Foram utilizados partes dos cursos 3 e 4 de acordo com os conteúdos abordados (sequência, laços, condicional, repetição, depuração, variáveis e funções) e o acompanhamento individual das alunas feito no próprio ambiente. A figura 1 mostra a aba "Estatísticas" selecionada e as informações de cada aluna com relação aos níveis concluídos, dentro das atividades propostas, e a quantidade de linhas de código escritas pela aluna. 


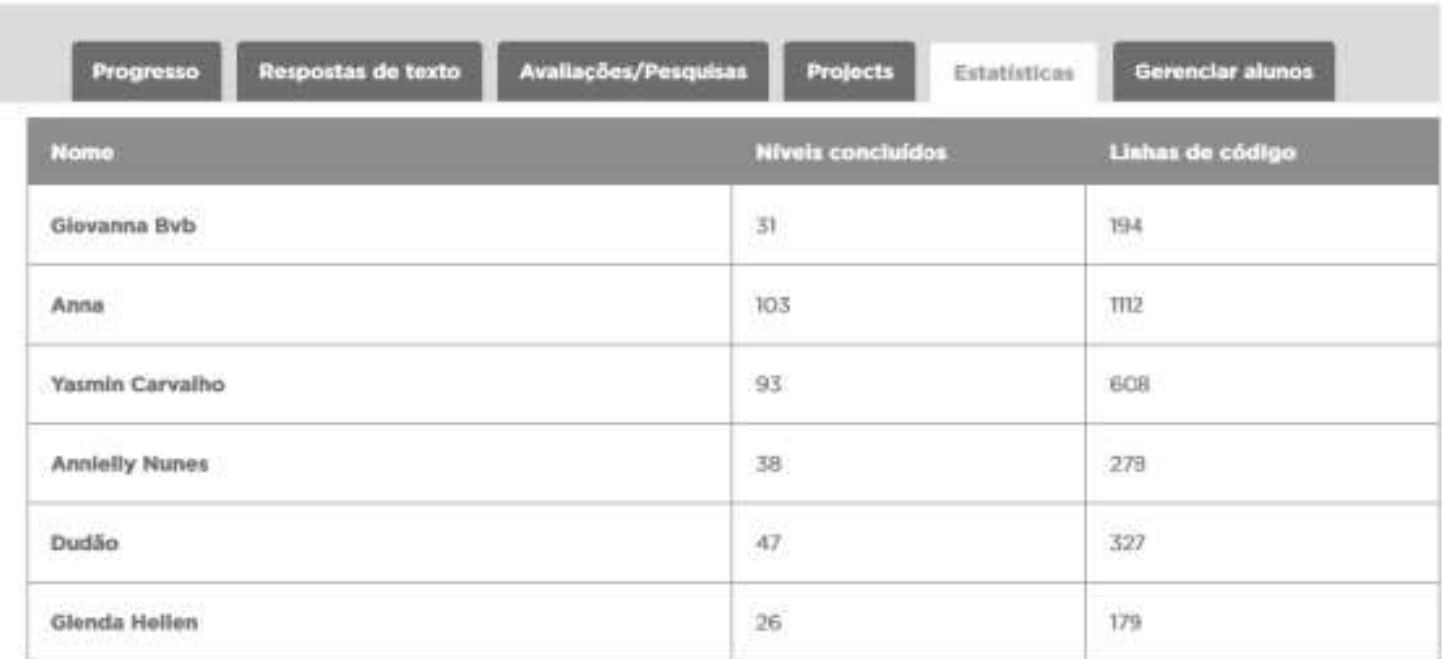

Figura 1. Acompanhamento das estatísticas individuais de cada aluna considerando os níveis concluídos e linhas de código escritas.

A figura 2 mostra a aba "Progresso" selecionada e o desempenho de cada aluna em cada uma das fases. É interessante destacar a importância desse acompanhamento pois através dele é possível identificar se as tarefas estão sendo realizadas com êxito ou não, pois a ferramenta verifica e analisa a quantidade de blocos/instruções que cada aluna está usando em cada fase.

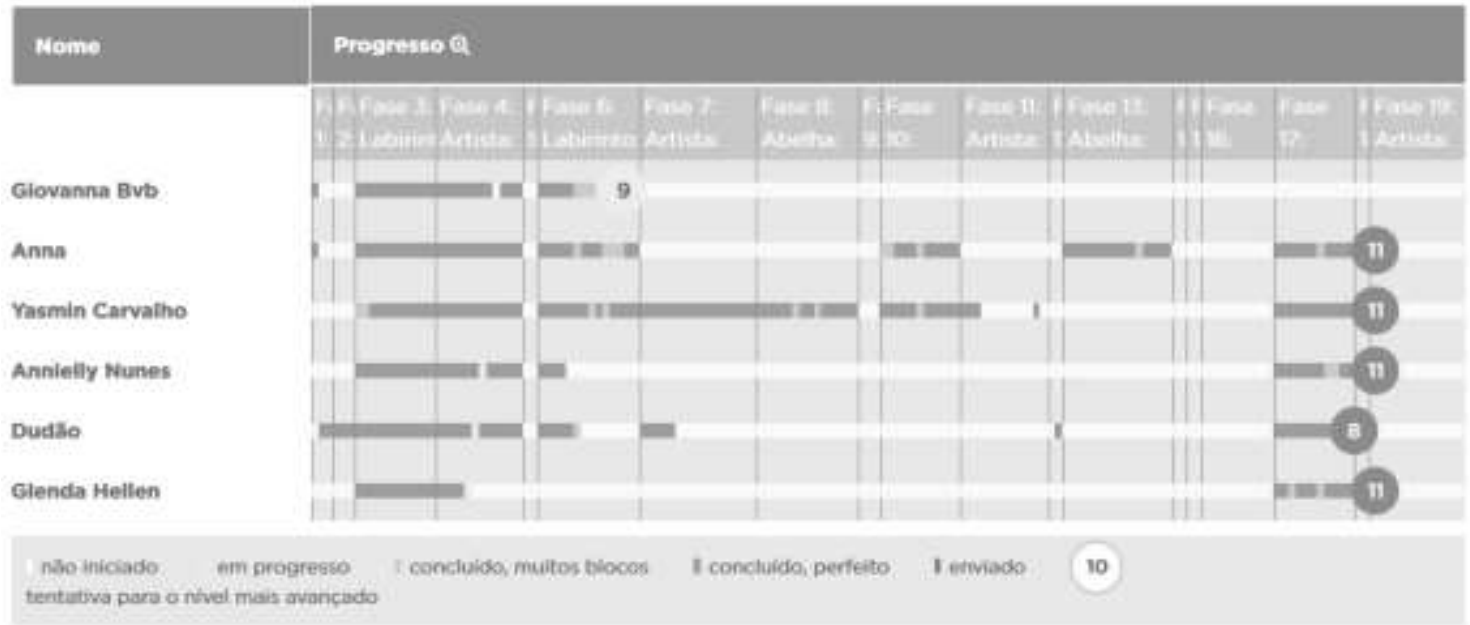

Figura 2. Progresso individual de cada aluna em cada uma das fases propostas na atividade.

A avaliação desta fase é feita utilizando os recursos disponibilizados pela ferramenta Studio Code, pela observação das instrutoras em sala de aula e pelas alunas. Algumas alunas consideram a atividade interessante porém cansativa devido à 
quantidade de tarefas selecionadas e muitas vezes repetidas dentro da mesma fase. As instrutoras observam a mesma situação, as alunas iniciam a atividade empolgadas mas ao longo dos encontros previstos elas reclamam da repetição.

$\mathrm{Na}$ última fase do projeto as alunas tem certa liberdade de criação pois colocam em prática os assuntos abordados no Studio Code. Para tal, já foram utilizadas as ferramentas Scratch e MIT App Inventor. Na ferramenta Scratch foram desenvolvidos pequenos jogos animados e no decorrer dos encontros as alunas foram aprimorando o jogo e inserindo novas funcionalidades à ele de acordo com os assuntos previstos. Alguns exemplos de tarefas desenvolvidas foram as simulações de movimentos de dança e dança ao sons de um tambor.

A atividade com o MIT App Inventor foi considerada bastante estimulante pelas instrutoras e alunas pois o desenvolvimento de aplicativos para dispositivos móveis é um tema atual e que desperta o interesse dos alunas. As atividades realizadas incluíram o desenvolvimento de uma Calculadora, uma Agenda e uma aplicação chamada de Papagaio (TalkToMe) onde a fala era convertida em texto e reproduzida em forma de som pelo aplicativo. De acordo com os relatos das instrutoras, as atividade foram realizadas satisfatoriamente pelas alunas com todas conseguindo realizar a sua aplicação e motivadas a incluir novas funcionalidades ao seu aplicativo. A figura 3 mostra as telas de dois aplicativos, Calculadora e Papagaio, desenvolvidos pelas alunas.
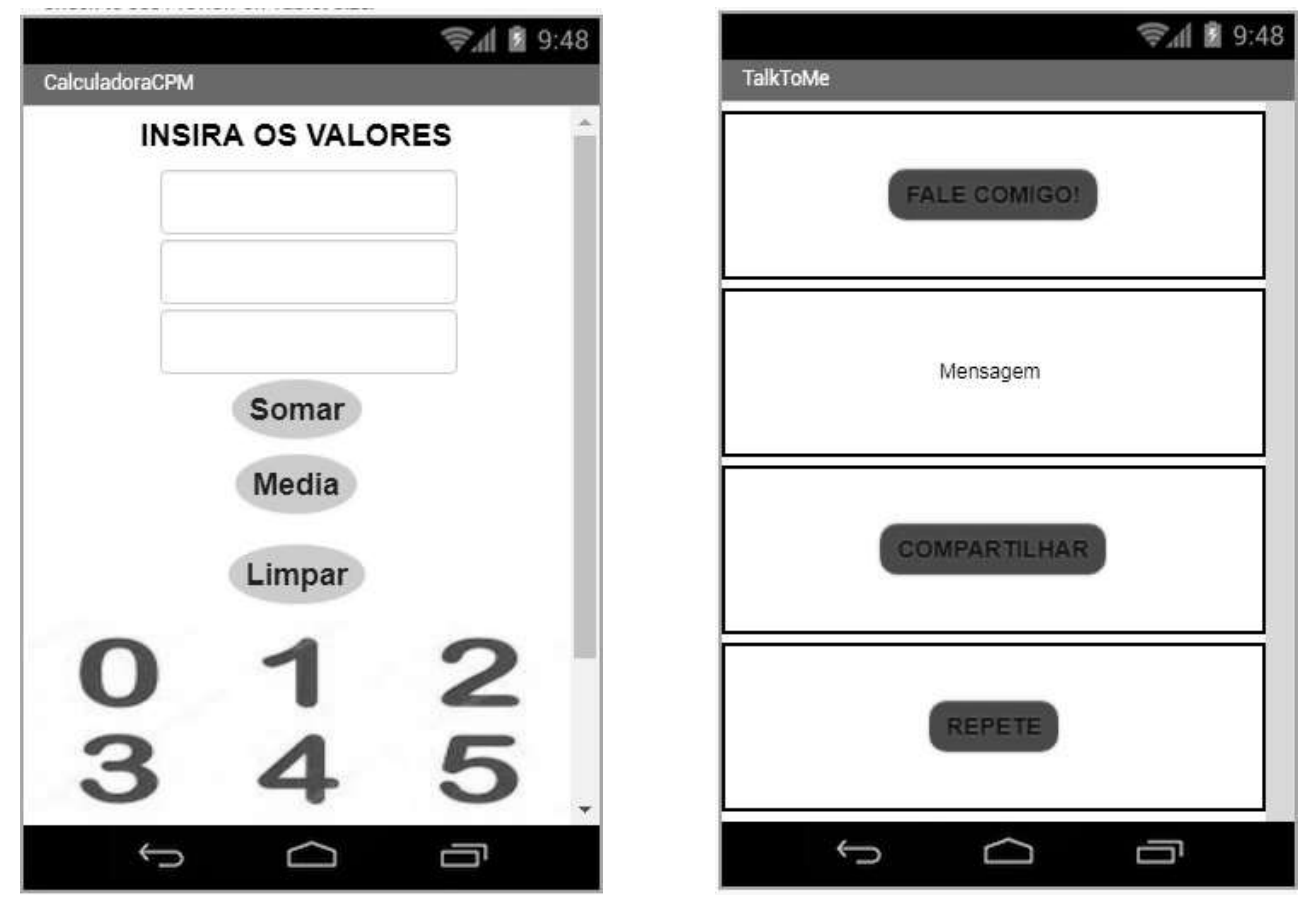

Figura 3. Tela dos aplicativos desenvolvidos.

$\mathrm{Na}$ avaliação realizada ao término do projeto anual foi aplicado um teste, que serviu para selecionar uma aluna bolsista PIBIC-EM (Ensino Médio), contendo 6 questões de lógica, nos mesmos moldes daquele aplicado na primeira atividade, e mais 4 questões retiradas de provas da Olimpíada Brasileira de Informática - Modalidade Iniciação. Cinco alunas participaram desta avaliação e a quantidade de acertos foi, 
respectivamente, 9, 8, 6, 5 e 3 questões. Quando perguntado a respeito das oficinas e a sua importância, todas elas relataram que se surpreenderam com as aulas, os conteúdos estudados e as ferramentas utilizadas bem como a sua satisfação pessoal em conseguir, elas mesmas, criar algo que possa ser útil a alguém.

\section{Considerações Finais}

A participação feminina em carreiras ou cursos de graduação ligados à Ciência e Tecnologia é baixa e inúmeras iniciativas vem sendo desenvolvidas, especialmente no Brasil, com o objetivo de mostrar às alunas do ensino fundamental e médio as reais possibilidades de atuação do profissional e o mercado de trabalho. Este relato apresentou as atividades que vem desenvolvendo há 3 anos no Colégio da Polícia Militar em João Pessoa-PB, junto as alunas do $1^{\circ}$ ano do ensino médio com o intenção de trabalhar conceitos básicos de programação de computadores e que estão presentes no dia a dia de todo profissional da área de Computação.

Os dados obtidos em pesquisas com as alunas mostram que poucas tem algum conhecimento prévio sobre programação e consideram a atividade de programar difícil. Muitas delas tem computador em casa e celular e as principais atividades realizadas são o acesso às redes sociais e jogos online. De maneira geral as alunas se sentem motivadas, interessadas e desafiadas com as atividades propostas, embora algumas destas atividades sejam consideradas massantes e repetitivas. $\mathrm{O}$ desenvolvimento de aplicativos com o MIT App Inventor foi a atividade mais desafiadora e estimulante pra elas pois puderam por em prática todos os conceitos estudados anteriormente com maior liberdade e criando as suas próprias aplicações. Embora seja um projeto de médio prazo, os primeiros resultados começam a aparecer. No vestibular de 2018 da UFPB tivemos uma aluna participante da primeira turma aprovada no concurso para um curso da área de Computação. Ainda não tivemos a oportunidade de fazer um acompanhamento e levantamento das escolhas profissionais das alunas participantes das oficinas até o ano de 2017. Os trabalhos futuros incluem este acompanhamento das escolhas profissionais, o impacto das oficinas de programação no rendimento escolar das alunas participantes bem como a revisão dos conteúdos abordados, das ferramentas utilizadas e a possibilidade de replicar o modelo apresentado para outras escolas da cidade.

A experiência das Oficinas de Programação junto ao público feminino vem sendo extremamente satisfatória sob dois aspectos principais: a participação das alunas do ensino médio que tem a oportunidade de aprender programação imersas em ambientes lúdicos e próprios para quem nunca programou; e a participação das alunas graduandas dos cursos da área de Computação que tem a possibilidade de compartilhar com a sociedade aquilo que vivenciam no ambiente acadêmico e o seu fortalecimento como profissional feminino da área.

\section{Referências}

Beaubouef, T. and Zhang, W. (2011) "Where are the women computer science students?" In: Journal of Computing Sciences in Colleges, Consortium for Computing Sciences in Colleges, USA, v. 26, n. 4, pages 14-20. 
Burge, J. D. and Suarez, T. L. (2005) "Preliminary Analysis of Factors Affecting Women and African Americans in the Computing Sciences" In: Proceedings of the 2005 Conference on Diversity in Computing, ACM, USA, pages 53-56.

Cohoon, J. M. (2002). Recruiting and retaining women in undergraduate computing majors. ACM SIGCSE Bulletin, 34(2), ACM, USA, pages 48-52.

DuBow, W. M. (2013) "Diversity in Computing: Why It Matters and How Organizations Can Archive It" Computer, IEEE Publisher, v.46, n.3, pages 24-29.

Eney, C., Lazowska, E., Martin, H. and Reges, S. (2013) "Broadening Participation: The Why and the How" Journal Gender Diversity in Computer, IEEE Publisher, v.46, n.3, pages $48-51$.

INEP. (2016) “Censo da Educação Superior 2016 - Principais Resultados”, http://download.inep.gov.br/educacao_superior/censo_superior/documentos/2016/ce nso_superior_tabelas.pdf.

Klawe, M. (2013) "Increasing Female participation in Computing: The Harvey Mudd College Story" Computer, IEEE Publisher, v. 46, n. 3, pages 56-58.

Maciel, C. and Bim, S. A. (2016) Programa Meninas Digitais - Ações Para Divulgar a Computação para Meninas do Ensino Médio. Computer on the beach 2016, https://siaiap32.univali.br/seer/index.php/acotb/article/view/10742, pages 327-336.

Mattos, G. O., Silva, D. R. D. and Moreira , J. A. (2015) “A Utilização de Kits de Robótica como Ferramenta para o Ensino de Programação à Meninas do Ensino Médio" In: XXIII Workshop sobre Educação em Computação, Publicado pela SBC, pages 2085-2093.

Ramos, N., Freitas, C., Avila, S., Costa, P. D. P., Testoni, V. and Borin, J. F. (2015) "Ensino de Programação para Alunas de Ensino Médio: Relato de uma Experiência" In: XXIII Workshop sobre Educação em Computação, Publicado pela SBC, pages 2089-2098.

Robins, A., Rountree, J. and Rountree, N. (2003). Learning and teaching programming: A review and discussion. Computer Science Education, 13(2), pages 137-172.

Sales, A., Calado, B., Silva, D. R. D., Mattos, G. O. and Moreira, J. A. (2014) "Dificuldades para o Ingresso e Permanência na Ciência e Engenharia da computação: Um Olhar Feminino" $18^{\circ}$ REDOR, Editora da UFPB, pages 3468-3482.

Souza, S. M., Rios, M. S., Rodrigues, C. A., Santos, D. M. B. and Bittencourt, R. A. (2013) "Oficinas de Programação com Ambientes Lúdicos Para Meninas do Ensino Fundamental”, In: XXI Workshop sobre Educação em Computação, Publicado pela SBC, pages 959-968.

Oliveira, A., Moro, M. M. and Prates, R. O. (2014) "Perfil Feminino em Computação: Análise Inicial", In: XXII Workshop sobre Educação em Computação, Publicado pela SBC, pages 1465-1474.

SBC. (2016) "Educação Superior em Computação - Estatísticas 2016" Disponível em http://sbc.org.br/documentos-da-sbc/send/133-estatisticas/1 167-educacao-superiorem-computacao-estatisticas-2016. 